\title{
Temporal range extension and evolution of the chasmosaurine ceratopsid 'Vagaceratops' irvinensis (Dinosauria: Ornithischia) in the Upper Cretaceous (Campanian) Dinosaur Park Formation of Alberta
}

\author{
James A. Campbell ${ }^{1,2}$, Michael J. Ryan², Claudia J. Schröder-Adams², \\ Robert B. Holmes ${ }^{3}$, and David C. Evans ${ }^{4}$
}

${ }^{1}$ Department of Biological Sciences, University of Calgary, 2500 University Drive NW, Calgary, Alberta, Canada, T2N 1N4; email: james.campbell2@ucalgary.ca

${ }^{2}$ Department of Earth Sciences, Carleton University, 1125 Colonel By Drive, Ottawa, Ontario, Canada, K1S 5B6; email:michaelpjryan@gmail.com, claudia.schroderadams@carleton.ca

${ }^{3}$ Department of Biological Sciences, University of Alberta, CW 405 Biological Sciences Building, Edmonton, Alberta, Canada, T6G 2E9; email: holmes1@ualberta.ca

${ }^{4}$ Department of Natural History, Royal Ontario Museum, 100 Queen’s Park, Toronto, Ontario, Canada, M5S 2C6; email: d.evans@utoronto.ca

\begin{abstract}
The Dinosaur Park Formation (DPF) has a diverse assemblage of chasmosaurines currently represented by Chasmosaurus belli, C. russelli, Vagaceratops irvinensis, and Mercuriceratops gemini, and may also include remains possibly referable to Spiclypeus shipporum. Two skulls, YPM 2016 and AMNH 5402, previously referred to C. belli, both have a straight posterior parietal bar with five epiparietals present (YPM 2016) or inferred (AMNH 5402) on each side - the combination of which is unique to V. irvinensis. Based on our new morphological observations and interpretations of these two skulls, we recover $V$. irvinensis as a species of Chasmosaurus (C. irvinensis), although the interrelationships between C. irvinensis, C. belli, and C. russelli remain unclear. We refrain from formally assigning YPM 2016 and AMNH 5402 to C. irvinensis, however, as their parietal fenestrae are significantly larger and their epiparietals are significantly shorter than those of $C$. irvinensis; instead, we reassign these two skulls to Chasmosaurus sp. Given the low stratigraphic position of YPM 2016 (unknown in AMNH 5402) relative to C. irvinensis, we believe this specimen to represent a basal member of the lineage leading to $C$. irvinensis. If our assessment is correct, this would indicate that the $C$. irvinensis lineage has a large degree of stratigraphic overlap with that of $C$. belli and C. russelli. The close phylogenetic relationship and supposed stratigraphic separation for these three taxa reported in previous studies were used to suggest that they may represent an anagenetic lineage, whereby $C$. russelli evolved into C. belli, and C. belli evolved into, and was entirely replaced by, C. irvinensis. However, the lack of stratigraphic separation between these three taxa indicates that they instead arose via cladogenesis.
\end{abstract}

\section{INTRODUCTION}

The Campanian Dinosaur Park Formation (DPF) of southern Alberta and Saskatchewan is characterized by a diverse assemblage of both chasmosaurines and centrosaurines, the former of which includes Chasmosaurus belli
(Lambe, 1902), C. russelli Sternberg, 1940, Vagaceratops irvinensis (Holmes et al., 2001), and Mercuriceratops gemini Ryan et al., 2014, and may also include material referable to Spiclypeus shipporum Mallon et al., 2016.

Vagaceratops irvinensis was originally described by Holmes et al. (2001) as Chasmosaurus irvinensis on the basis of a 
relatively complete skull and associated skeleton (CMN 41357, holotype), and two referred partial skulls (TMP 1987.045.0001 and TMP 1998.102.0008) from Alberta (Figs. 1, 2). Since their initial description, two additional partial skulls (TMP 2009.034.0009, Longrich 2010; TMP 2011.053.0046, Campbell et al. 2018) have been assigned to this taxon. Holmes et al. (2001) assigned this species to Chasmosaurus (C. irvinensis), as their phylogenetic analysis recovered it as the sister taxon to $C$. belli. Holmes et al. (2001:1424), in distinguishing C. irvinensis from C. belli and $C$. russelli, noted its possession of a "transversely broad snout; nasal horn core short and transversely broad; brow [= postorbital] horn [core] absent, its normal position occupied by a low, raised, rugose boss, in one specimen bearing a large, smooth surfaced, hemispherical resorption pit; jugal notch on anterior squamosal broadly rounded and open (not parallel-sided); squamosal tapers little posteriorly, subrectangular in outline, and projects almost directly laterally ... [p] osterior parietal bar straight in anterior and dorsal aspects, projects only slightly posterior to the squamosal; maximum diameter of parietal fenestra less than length of preorbital region of the skull ... [t] en epoccipitals [= epiossifications] on posterior parietal bar, lateral ... [epiossification] low and shield-shaped, the remaining eight nearly indistinguishably coossified together, and composed of flattened posteroventral laminae that wrap around the back of the bar, and larger laminae that curve strongly dorsally and anteriorly over the bar."

Sampson et al. (2010) described Kosmoceratops richardsoni (UMNH VP 17000, holotype) from the Campanian Kaiparowits Formation of southern Utah as also having five pairs of epiossifications on the posterior frill margin. However, based on the location of the parietal-squamosal suture, they identified the three medialmost pairs as epiparietals, the fourth pair as epiparietosquamosals, and the fifth pair as episquamosals for this taxon. As the parietal-squamosal suture is difficult to discern in the holotype of $C$. irvinensis, likely as a result of advanced age for this individual (Holmes 2014), Sampson et al. (2010) concluded that it probably lies below the fourth epiossification, as in

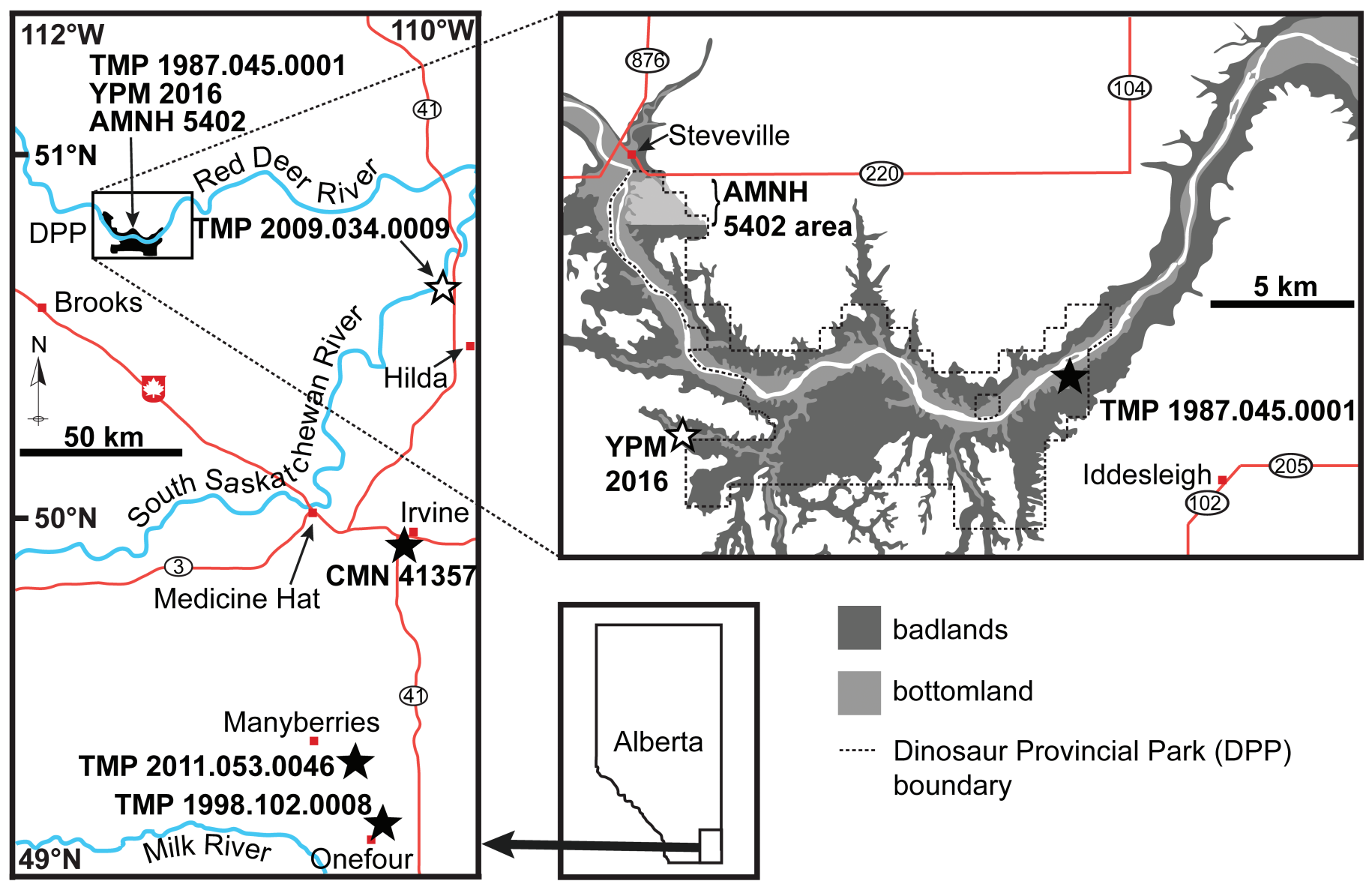

Figure 1. Regional map of localities producing 'Vagaceratops' irvinensis specimens (solid black stars; CMN 41357, TMP 1987.045.0001, TMP 1998.102.0008, and TMP 2011.053.0046) and 'V.' irvinensis-like Chasmosaurus sp. specimens (empty black stars; AMNH 5402, TMP 2009.034.0009, and YPM 2016). AMNH 5402 was collected "in Township 21, Range 12, about 1 mile below Steveville, on the left bank of the river" (Lull 1933:12); the general area this encompasses is shown in light grey. 
$K$. richardsoni. Due to their reinterpretation of $C$. irvinensis, they recovered it as the sister taxon to K. richardsoni in their phylogenetic analysis, and, accordingly, placed C. irvinensis into a new genus, Vagaceratops.

Longrich (2014) identified ten epiparietals on the holotype of $V$. irvinensis (sensu Holmes et al. 2001) and recovered this species as the sister taxon to C. belli in his phylogenetic analysis. Although he referred to the former species as $C$. irvinensis, he did not formally reassign this species to Chasmosaurus.

Campbell et al. (2016) later identified five pairs of epiparietals on a skull previously referred to C. belli (YPM 2016), in which the parietal-squamosal suture is visible. They also interpreted the five pairs of epiossifications in $V$. irvinensis as either representing five pairs of epiparietals (i.e., CMN 41357), or four pairs of epiparietals and one pair of epiparietosquamosals (i.e., TMP 1987.045.0001). In their specimen-based phylogenetic analysis, they recovered a weakly-supported clade containing V. irvinensis (CMN 41357 and TMP 1987.045.0001), YPM 2016, and AMNH 5402 (another skull previously referred to $C$. belli), which had an unresolved relationship with other Chasmosaurus specimens (Fig. 3A). Although Chasmosaurus and Vagaceratops specimens formed a single, larger clade, their unresolved relationship made it difficult to say whether these genera were synonymous or distinct. Campbell et al. (2016) tentatively concluded that the frill of Vagaceratops is sufficiently distinct from that of Chasmosaurus to merit its own genus. They also tentatively retained YPM 2016 and AMNH 5402 within $C$. belli, but noted that the similarities between YPM 2016, AMNH 5402, and V. irvinensis specimens would be discussed in a future publication. These two specimens are the subject of the present study.

\section{Geology and Biostratigraphy of the Dinosaur Park Formation}

The Belly River Group is a predominantly terrestrial sedimentary sequence deposited along the western margin of the Western Interior Seaway, and includes, in ascending stratigraphic order, the Foremost, Oldman, and Dinosaur Park formations (Eberth 2005). The contact between the Oldman and Dinosaur Park formations is diachronous, due to the wedge-shaped geometries of these two units. The DPF is $70 \mathrm{~m}$ thick in Dinosaur Provincial Park (DPP), but thins moving southwards, and is approximately $20 \mathrm{~m}$ thick in Onefour, Alberta (Eberth and Hamblin 1993; Eberth 2005). As a result, the upper sediments of the Oldman Formation in Onefour are time-equivalent to the lower to middle DPF in DPP. Alluvial and paralic sediments of the DPF document an overall transgression, transitioning from sandy to muddy to coaly (Lethbridge Coal Zone; LCZ) intervals, and overlain by fully-marine shales of the Bearpaw Formation.
The DPF has also been subdivided into three distinct faunal zones, with each one characterized by a unique assemblage of centrosaurine and lambeosaurine taxa (Ryan and Evans 2005; Ryan et al. 2012; Fig. 2). These Dinosaur Park faunal zones are, in ascending stratigraphic order: Centrosaurus-Corythosaurus Zone (0-30 m above the Oldman Formation in DPP), Styracosaurus-Lambeosaurus lambei Zone (30-50 $\mathrm{m}$ above the Oldman Formation in DPP), and Lambeosaurus magnicristatus-pachyrhinosaur Zone (50-70 $\mathrm{m}$ above the Oldman Formation in DPP). Chasmosaurus russelli, C. belli, and V. irvinensis were also thought to be constrained to these three zones, respectively (Ryan and Evans 2005; Ryan et al. 2012). However, Campbell et al. (2016) recently demonstrated that skulls previously referred to $C$. russelli span all three zones, as the holotype was actually collected from the upper (Lambeosaurus magnicristatus-pachyrhinosaur) zone.

\section{ABBREVIATIONS}

Anatomical Abbreviations: es, episquamosal; es lc, episquamosal locus; ltf, lateral temporal fenestra; nhc, nasal horncore; ns, nares; orb, orbit; p, epiparietal; p lc, epiparietal locus; pa, parietal; paf, parietal fenestra; p-es, epiparietosquamosal; pohc, postorbital horncore; pom, postorbital mound; sq, squamosal.

Institutional Abbreviations: AMNH, American Museum of Natural History, New York, NY, U.S.A.; CMN, Canadian Museum of Nature, Ottawa, ON, Canada; ROM, Royal Ontario Museum, Toronto, ON, Canada; TMP, Royal Tyrrell Museum of Palaeontology, Drumheller, AB, Canada; UMNH VP, Utah Museum of Natural History Vertebrate Paleontology Collections, Salt Lake City, UT, U.S.A.; YPM, Yale Peabody Museum, New Haven, CT, U.S.A.

\section{REDESCRIPTION OF YPM 2016 AND}

\section{AMNH 5402}

YPM 2016 (Figs. 2, 4I, J, 5E, F) was collected by C.M. Sternberg (Geological Survey of Canada) as field specimen 2-1919 in 1919 (Campbell et al. 2016). Sternberg (1919:3) noted that this specimen was collected "about 65 $\mathrm{ft}$ below Pierre Shale on the south side of the west branch of Little Sand Hill Creek within about 3/4 of a mile from where the badlands give way to grass-covered slopes." Lull (1933:12) provided a less detailed and miscopied account of Sternberg's notes, writing that YPM 2016 was collected "on the south side of the west branch of Little Sandhill Creek, 60 feet below the overlying Pierre shales." Sometime between 1935 and 1936, Sternberg revisited the site and marked it with a stake, and this site is now known as 


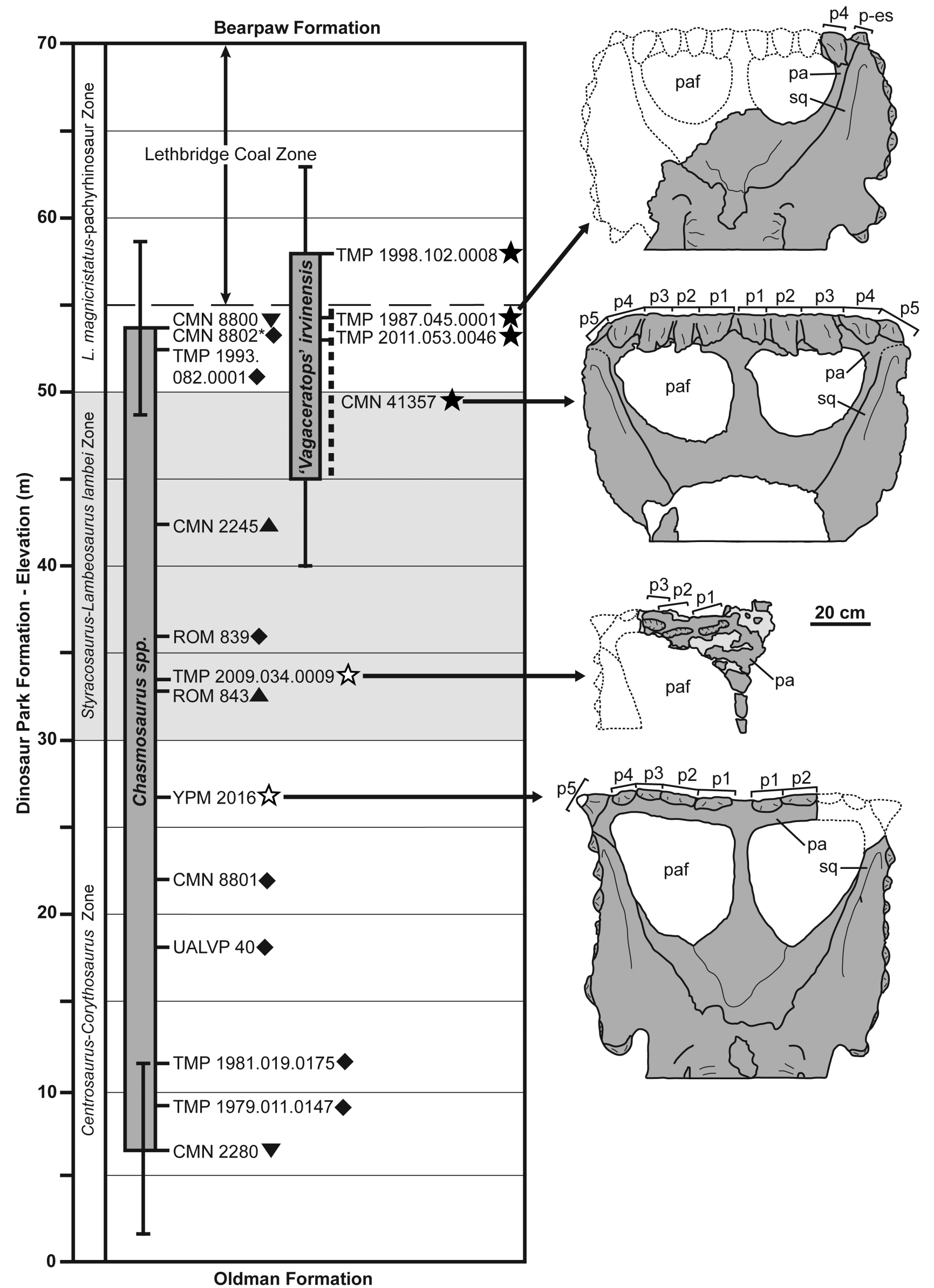


Quarry 110 (Sternberg 1936; Currie and Russell 2005). The stratigraphic elevation of Quarry 110 was reported by Godfrey and Holmes (1995) as being $31.4 \mathrm{~m}$ above the base of the DPF, and amended by Campbell et al. (2016) as being $26.5 \mathrm{~m}$ above the base of the DPF.

The stratigraphic elevation of YPM 2016, as reported by Lull (1933), is inconsistent with Godfrey and Holmes' (1995) reported elevation of Quarry 110. Lull (1933) reported the elevation of the specimen as being 65 feet (approximately $18.3 \mathrm{~m}$ ) below the Pierre Shale, which, in southern Alberta, is actually the shales of the Bearpaw Formation. This would place the specimen somewhere between 50 and $60 \mathrm{~m}$ above the base of the DPF, which is approximately $20 \mathrm{~m}$ higher than Godfrey and Holmes' (1995) reported elevation of Quarry 110.

However, Sternberg's (1919) more detailed locality description is consistent with the location of Quarry 110 (Currie and Russell 2005). Quarry 110 is located west of the core area of DPP, in a privately-owned area of badlands. As one moves westwards from the core area of DPP, the upper portion of the DPF becomes progressively less exposed, such that neither the LCZ nor the overlying Bearpaw Formation are exposed in the broad area of badlands surrounding Quarry 110 (MJR, pers. obs.). This suggests that Sternberg's (1919) estimation of the elevation of YPM 2016 below the Bearpaw Formation was based on distantly exposed outcrops of that formation and is not reliable. We therefore believe that Quarry 110 is indeed the source of YPM 2016 (Currie and Russell 2005), and that this quarry lies approximately $26.5 \mathrm{~m}$ above the base of the DPF (Campbell et al. 2016).

AMNH 5402 (Figs. 4K, 5G, H) was collected by P.C. Kaisen and B. Brown (AMNH) in 1913, "in Township 21, Range 12, about 1 mile below Steveville, on the left bank of the [Red Deer] river" (Lull 1933:12). The Red Deer River flows southward in this latter area, and, to the perspective of someone who is facing downstream, the east bank would be to the left. Lull (1933:12) also stated that AMNH 5239 (holotype of Monoclonius flexus, now a referred specimen of Centrosaurus apertus) was collected by the AMNH in 1912 "about 1 mile below Steveville, [also] on the left bank of the [Red Deer] river." AMNH 5239 was collected by Barnum Brown from Quarry 57 in Dinosaur Provincial Park (Currie and Russell 2005), which is situated on the east side of the Red Deer River. We therefore interpret that AMNH 5402 was collected on the east side of the Red Deer River. About one mile downstream of Steveville, the east side encompasses a laterally and stratigraphically extensive area of outcrop, informally known as the 'Steveville badlands' (Fig. 1; Farke et al. 2011). AMNH 5402 was most likely collected from the DPF, as chasmosaurines have not yet been recorded from the Oldman Formation within the DPP area (Ryan and Evans 2005). A chasmosaurine skull (Chasmosaurus sp.) is known from sediments of the uppermost Oldman Formation in the Onefour area of southeastern Alberta, although these sediments are time-equivalent with the DPF as exposed in DPP, and significantly younger than the Oldman Formation as exposed in DPP (Campbell et al. 2018).

YPM 2016 and AMNH 5402 were both previously referred to C. belli, based on their possession of a relatively straight posterior parietal margin - a feature considered to be diagnostic of this species within Chasmosaurus (Lull 1933; Godfrey and Holmes 1995; Maidment and Barrett 2011; Campbell et al. 2016). However, instead of having three, evenly-spaced epiparietals on each side of the posterior parietal bar, as per Chasmosaurus (e.g., CMN 2280, CMN 8800, ROM 843, TMP 1983.021.0001, TMP 1999.055.0292), Campbell et

\section{$\leftarrow$ Opposite Page}

Figure 2. Stratigraphic positions of 'Vagaceratops' irvinensis (solid black stars), 'V.' irvinensis-like Chasmosaurus sp. (empty black stars), C. belli (triangles), C. russelli (inverted triangles), and Chasmosaurus sp. (diamonds) specimens from the Dinosaur Park Formation (DPF), and age-equivalent sediments (i.e., CMN 8802, denoted by asterix), of Alberta. Stratigraphic data from Campbell et al. (2016, 2018), except for CMN 41357, TMP 1998.102.0008, and TMP 2009.034.0009 (see below). Specimens above the regional disconformity ( $\mathrm{o} \mathrm{m}$ ) separating the Dinosaur Park and Oldman formations (error bars $\pm 5 \mathrm{~m}$ ). Specimens from the Onefour/Manyberries area (i.e., CMN 8800, CMN 8802, TMP 1998.102.0008, and TMP 2011.053.0046) are placed in section using their estimated elevation below the Lethbridge Coal Zone (LCZ), which is thought to be an approximate chronostratigraphic datum across southern Alberta (Eberth 1996). CMN 8802 was collected below the LCZ, from the uppermost Oldman Formation near Onefour, which is time-equivalent to the upper half of the DPF as exposed in Dinosaur Provincial Park (Campbell et al. 2018). CMN 41357 was likely collected from a horizon between 0 and $10 \mathrm{~m}$ below the base of the LCZ (MJR, pers. obs.), but the precise horizon is unknown. TMP 1998.102.0008 was collected near Onefour from the basal lag bonebed in Complex Mud-Filled Incised Valley No. 1, which lies approximately $3 \mathrm{~m}$ above the base of the LCZ (Eberth 1996: fig. 12); however, due to the depth of the incision cut (approximately $16 \mathrm{~m}$ ), this specimen may be much younger. TMP 2009.034.0009 was collected from a horizon approximately $33.5 \pm 5 \mathrm{~m}$ above the Oldman Formation (D. Eberth, pers. comm.). Parietosquamosal frills of select 'V.' irvinensis and 'V.' irvinensis-like Chasmosaurus sp. skulls are shown in dorsal view on right, in ascending stratigraphic order; dashed line in CMN 41357 marks estimated sutural boundary between parietal and squamosal; plaster reconstruction in CMN 41357 and YPM 2016 = white. 


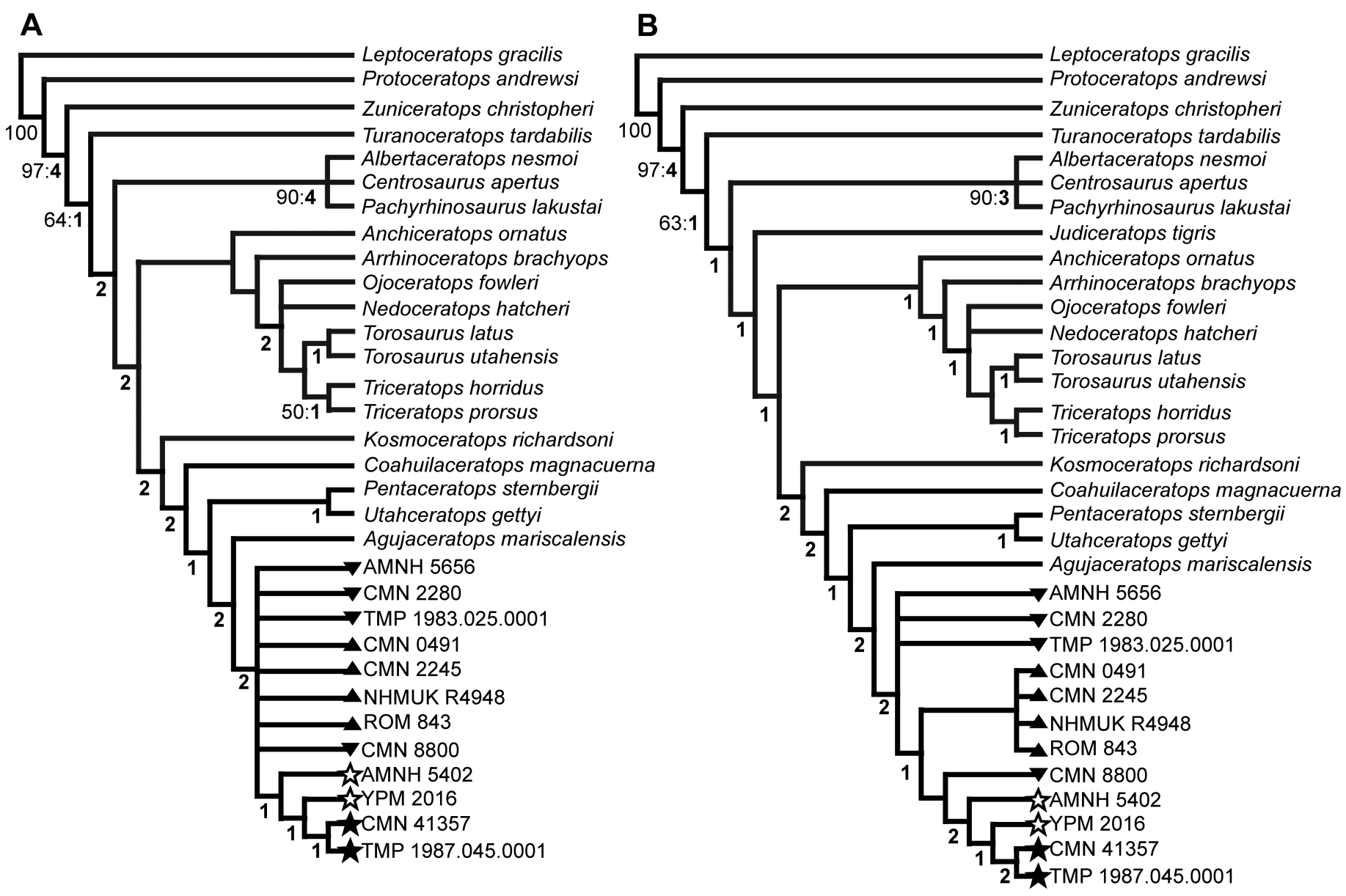

Figure 3. Specimen-based phylogenetic analyses of Chasmosaurus and 'Vagaceratops' specimens. A) Strict consensus tree of Campbell et al. (2016: fig. 5D, modified), excluding Bravoceratops, Eotriceratops, Judiceratops, and specimens missing the diagnostic posterior parietal region (AMNH 5401, CMN 1254, ROM 839, TMP 1981.019.0175, and UALVP 40); 5410 most parsimonious trees (MPTs), tree length $(\mathrm{TL})=276 \mathrm{steps}$, consistency index $(\mathrm{Cl})=0.64$, retention index $(\mathrm{RI})=0.76)$. B) Strict consensus tree with same taxa and specimens excluded, except for Judiceratops, and with revised recodings for AMNH 5402 (see text); 1530 MPTs, $\mathrm{TL}=291$ steps, $\mathrm{Cl}=0.63, \mathrm{RI}=0.76$ ). Bootstrap replicate frequency and Bremer support (bold) values are shown below each node; only Bootstrap values of $50 \%$ or higher are given. 'Vagaceratops' irvinensis (solid black stars), 'V.' irvinensis-like Chasmosaurus sp. (empty black stars), C. belli (triangles), and C. russelli (inverted triangles) specimens.

al. (2016) identified five on the right side of YPM 2016 (Fig. 4I, J) as per the holotype of $V$. irvinensis (CMN 41357, Fig. 4A, B). Differences from the Vagaceratops condition include: the four medialmost epiparietals of YPM 2016 are short and do not overhang the posterior parietal bar; they are not coalesced at their bases; and, the parietal fenestra length-to-width ratio of YPM 2016 (1.03; Fig. 2) is larger than that of CMN 41357 (0.72; Fig. 2), but not as large as those of other Chasmosaurus skulls $(\mathrm{ROM} 843=1.09$ to $\mathrm{AMNH} 5656=1.89$; Campbell et al. 2016); the ratio for AMNH 5402 is 1.04 (Campbell et al. 2016: fig. 21).

Campbell et al. (2016) identified three epiparietals on the better-preserved left side of AMNH 5402 (Fig. 4K, L). However, they noted that their arrangement is unusual, with the first and second medialmost epiparietal being separated by a relatively wide gap. They also identified

Opposite Page $\rightarrow$

Figure 4. Posterolateral corner of parietosquamosal frills of Chasmosaurus irvinensis (solid black stars) and C. irvinensis-like Chasmosaurus sp. (empty black stars) in dorsal view. (A-B) CMN 41357 (C. irvinensis holotype, cast; left side); (C-D) TMP 1987.045.0001 (left side); (E-F) TMP 1998.102.0008 (left side); (G-H) TMP 2009.034.0009 (right side, reflected); (I-J) YPM 2016 (right side, reflected); (K-L) AMNH 5402 (left side). Brackets delimit size of epiossifications; arrows denote inferred epiparietal attachment loci (low-relief undulations); dashed lines inferred reconstructed bone; dashed line in (B) marks estimated sutural boundary between parietal and squamosal; plaster reconstruction $=$ white. 


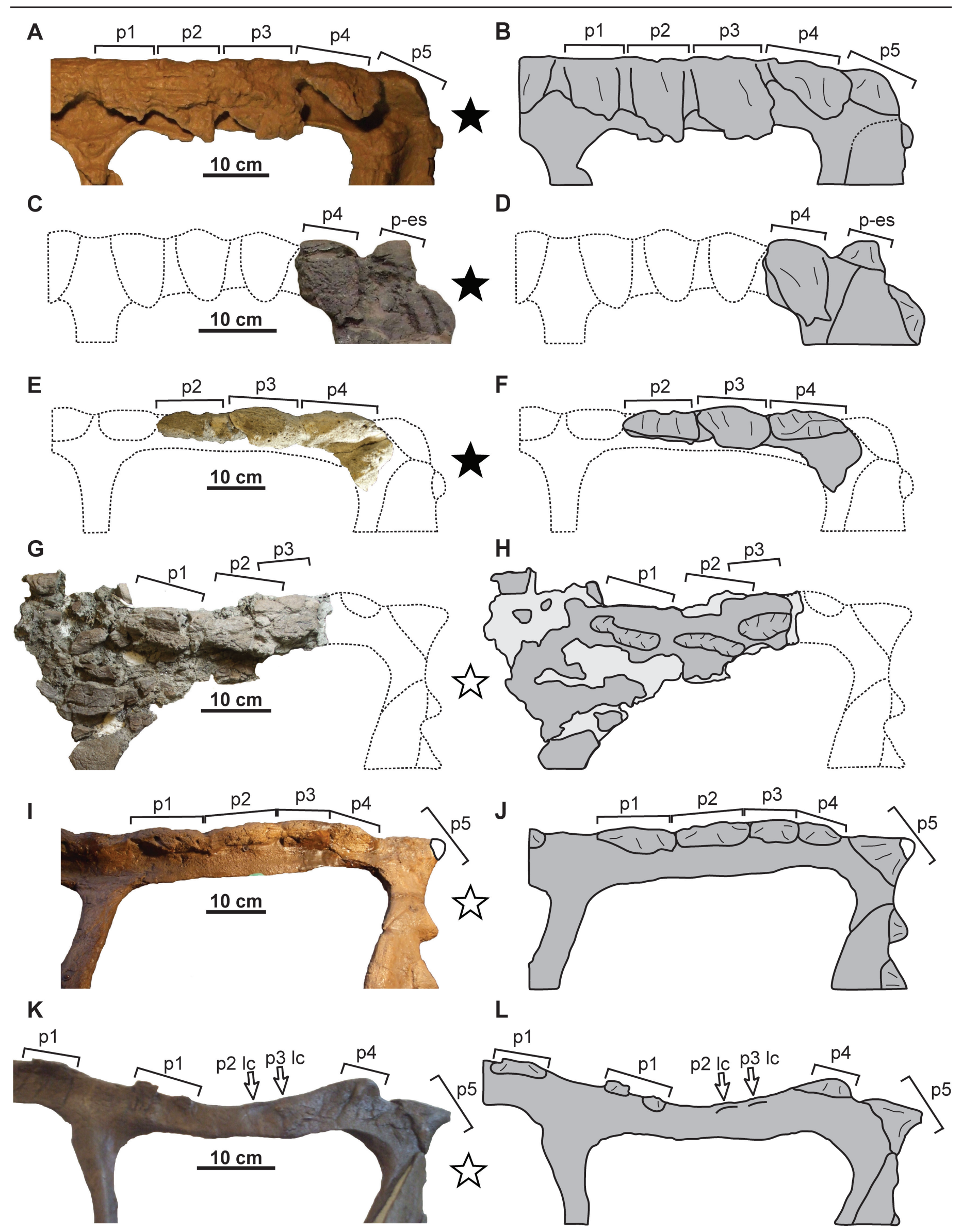


two low-relief parietal undulations along this gap, and in the equivalent region of the right side of the frill, but did not provide an explanation to account for their presence. The spacing between epiossifications in a ceratopsid frill is relatively uniform, suggesting that the wide gap in $\mathrm{AMNH}$
5402 was once occupied by epiparietals, but were unfused and fell off post-mortem. These undulations are also similar to the partly exposed epiparietal attachment locus underlying the left medialmost epiparietal (epiparietal 1). We therefore interpret the parietal undulations of AMNH
A
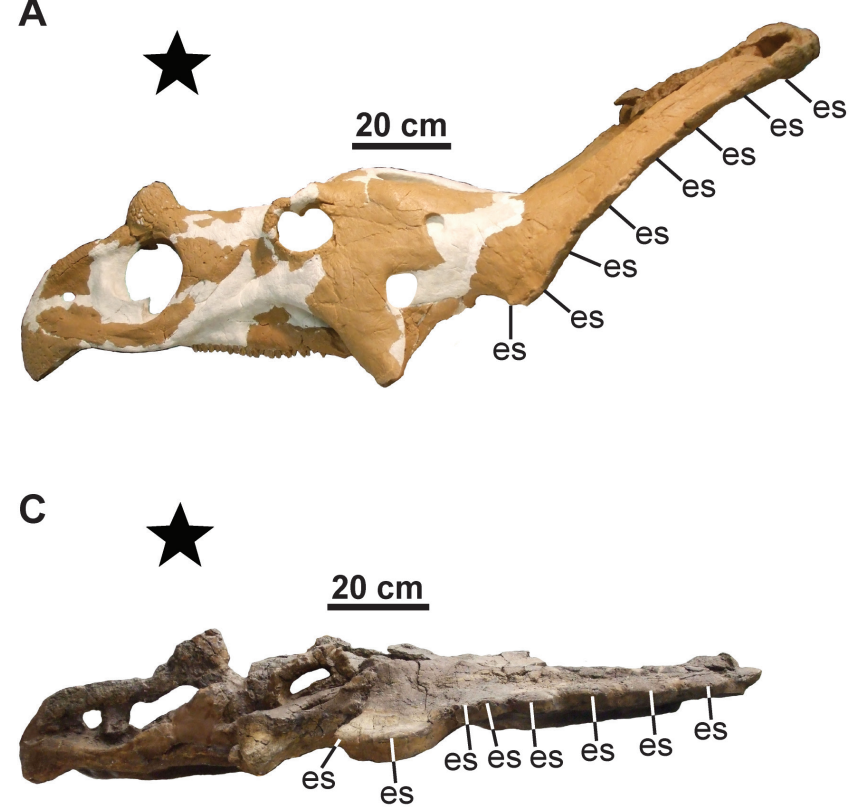

E
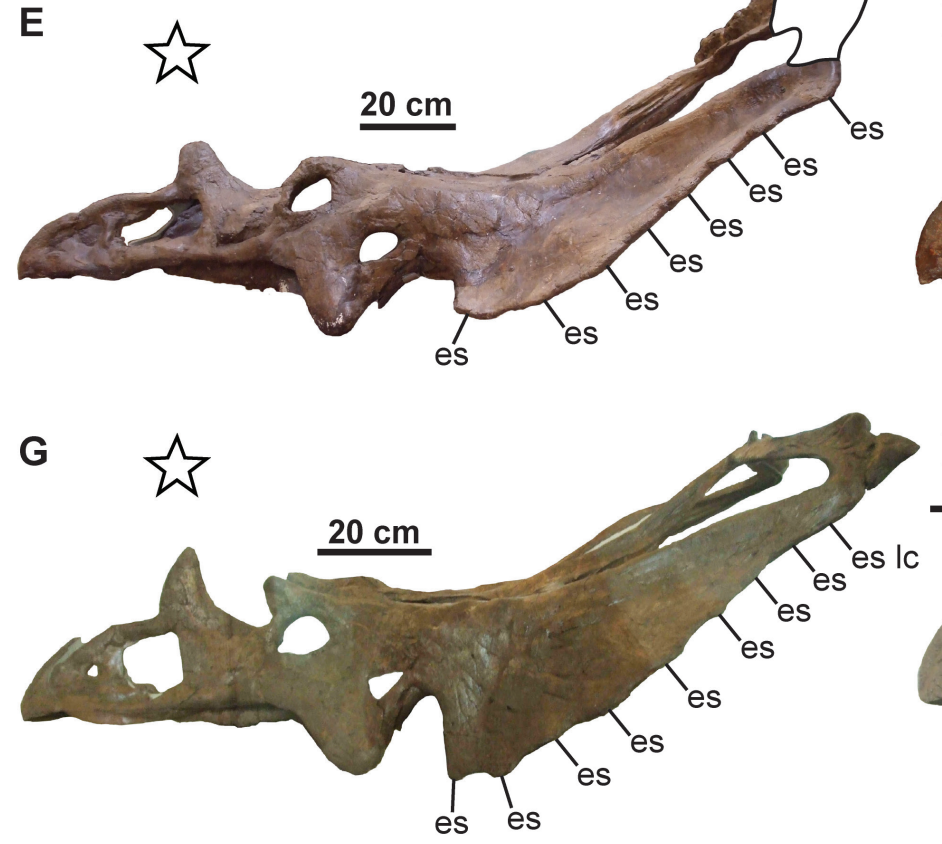
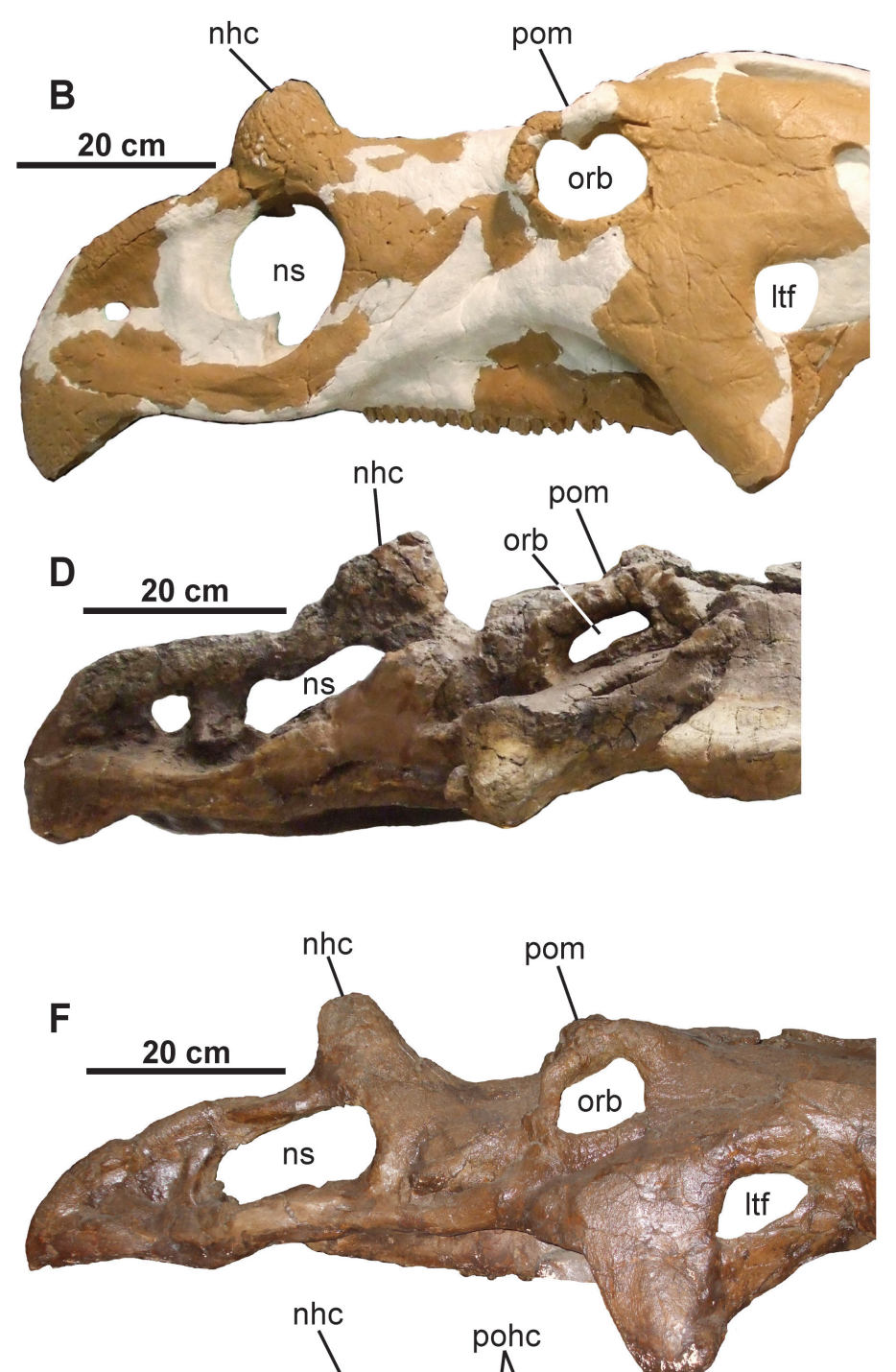

Figure 5. Skulls of Chasmosaurus irvinensis (solid black stars) and C. irvinensis-like Chasmosaurus sp. (empty black stars) in lateral view. (A-B) CMN 41357 (C. irvinensis holotype, cast; right side, flipped); (C-D) TMP 1987.045.0001 (left side); (E-F) YPM 2016 (left side); (G-H) AMNH 5402 (left side). Note that postorbital horncores are present on AMNH 5402, whereas rugose, postorbital mounds are present in all other skulls. Plaster reconstruction = white. 
5402 as attachment loci for two additional, similarly-sized epiparietals, for a total of five epiparietals on each side. The preserved epiparietals in AMNH 5402 (Fig. 4K, L) occupy homologous positions as epiparietals 1, 4, and 5 in CMN 41357 (Fig. 4A, B) and YPM 2016 (Fig. 4I, J), and are identified as such in this study.

\section{PHYLOGENETIC ANALYSIS}

A phylogenetic analysis was performed using the matrix of Campbell et al. (2016). This matrix consists of 155 characters and 40 operative taxonomic units (OTUs), the latter of which includes 23 ceratopsian taxa, and 17 specimens previously referred to Chasmosaurus and Vagaceratops. The phylogenetic analysis of Campbell et al. (2016) was re-run using the same settings as follows, and the above revised codings for AMNH 5402 (see Appendix 1) were included. The analysis was performed using the tree bisection reconnection search algorithm, starting with Wagner trees, with a random seed of one, with 10 trees saved per replication $(\mathrm{n}=$ 1000), and with Leptoceratops assigned as the outgroup. All characters were treated as unordered. The analysis (strict consensus tree) and corresponding tree statistics (Bootstrap and Bremer support) were conducted in TNT 1.1 (Goloboff et al. 2003, 2008). Bootstrap values were calculated using 1000 replicates. Consistency $(\mathrm{CI})$ and retention (RI) indices were obtained in PAUP $4 \mathrm{~b} 10$ (Swofford 2002) using the matrix assembled in Mesquite v.2.75 (Maddison and Maddison 2011). The matrix is provided in Appendix 2.

The analysis produced a strict consensus tree with a mostly well-resolved Chasmosaurinae clade. Specimens of Chasmosaurus and Vagaceratops form a monophyletic clade, with the clade (YPM $2016+(\mathrm{CMN} 41357+$ TMP 1987.045.0001)) forming a polytomy with all other specimens except for AMNH 5401 (Chasmosaurus sp.), which forms an outgroup. Resolution within the Chasmosaurinae clade was slightly improved with the subsequent exclusion of the fragmentary taxa Bravoceratops and Eotriceratops (sensu Campbell et al. 2016). The further exclusion of the fragmentary Judiceratops had no effect on the resolution of the Chasmosaurinae clade and was retained in later tree iterations. In an attempt to improve the resolution within the (Chasmosaurus + Vagaceratops) clade, the specimens missing their diagnostic posterior parietal regions (AMNH 5401, CMN 1254, ROM 839, TMP 1981.019.0175, and UALVP 40) were excluded (sensu Campbell et al. 2016). This greatly improved the resolution within the clade of this tree (Fig. 3B; 1530 most parsimonious trees, tree length $=291$ steps, $\mathrm{CI}=0.63, \mathrm{RI}=0.76)$, yielding the clade $(\mathrm{CMN} 8800+(\mathrm{AMNH} 5402+(\mathrm{YPM} 2016+(\mathrm{CMN}$ 41357 + TMP 1987.045.0001)))), an unresolved sister clade including specimens previously referred to $C$. belli
(CMN 0491, CMN 2245, NHMUK R4948, and ROM $843)$; the remaining specimens are specimens previously referred to C. russelli (AMNH 5656, CMN 2280, and TMP 1983.025.0001), which form a polytomic relationship. The (Chasmosaurus + Vagaceratops) clade and clades therein are weakly supported, with Bootstrap values all below 50\%, and Bremer values range from 0 to 2 (Fig. 3B). The best supported clades are the (Chasmosaurus + Vagaceratops), (CMN $41357+$ TMP 1987.045.0001), and $($ AMNH $5402+($ YPM $2016+($ CMN $41357+$ TMP 1987.045.0001))) clades, with Bremer values of 2; the latter two clades are better supported than in the analysis of Campbell et al. (2016; Fig. 3A), which recovered Bootstrap values of 1 . The most weakly supported clade is the one containing specimens previously referred to $C$. belli, with a Bremer value of 0 .

\section{DISCUSSION}

Campbell et al. (2016) did not refer YPM 2016 or AMNH 5402 to Vagaceratops irvinensis, but instead tentatively attributed the source of their unusual features to individual variation within $C$. belli. These specimens either have (YPM 2016) or are inferred to have had (AMNH 5402) five epiossifications on the posterior parietal margin, as well as a straight posterior parietal margin. This combination of characters is unique to $V$. irvinensis, suggesting that these two specimens are closely related, if not referable to, this species. However, YPM 2016 and AMNH 5402 are also similar to $C$. belli and C. russelli skulls, in that they possess postorbital horncores, their epiparietals are relatively short and not coossified with each other at their bases, and their parietal fenestrae are relatively long. The intermediate morphologies of YPM 2016 and AMNH 5402 makes their species-level assignment problematic. While it could be argued alternatively that YPM 2016 and AMNH 5402 belong to a new species, we believe that they most likely represent stratigraphically-basal members of the $V$. irvinensis clade (see below). Given their intermediate morphology, however, we tentatively assign YPM 2016 and AMNH 5402 to Chasmosaurus sp. TMP 2009.034.0009 is a poorly preserved and fragmented specimen, although the preserved epiparietals (interpreted herein as epiparietals 1 , 2, and 3; Fig. 4G, H) are relatively short, similar to those of YPM 2016. Given the similarity of these latter two skulls, we also reassign TMP 2009.034.0009 to Chasmosaurus sp. One study (Sampson et al. 2010) has suggested that $V$. irvinensis is actually more closely related to Kosmoceratops, and as such, should be moved to the new genus, Vagaceratops. Subsequent studies have also recovered Kosmoceratops and Vagaceratops as sister taxa (Mallon et al. 2011; Wick and Lehman 2013; Mallon et al. 2014; 
Campbell 2015; and Brown and Henderson 2015), but the character-taxon matrices used in these studies are modified from that of Sampson et al. (2010) and retain the original coding of three epiparietals per side (Character 93, state 1 of Sampson et al. 2010) for both of these genera. Mallon et al. (2016) modified the Brown and Henderson (2015) matrix, and recoded Vagaceratops as having five epiparietals per side (sensu Campbell et al. 2016; Character 93, state 1 of Campbell et al. 2016), and C. belli as having both three and five per side (sensu Campbell et al. 2016; states 0 and 1 , respectively); the polymorphic state for C. belli was done to account for the condition in YPM 2016 (sensu Campbell et al. 2016). Mallon et al. (2016) also recoded Vagaceratops as lacking a concave median embayment on the posterior parietal margin (sensu Campbell et al. 2016; Character 66, state 1 of Sampson et al. 2010), unlike the embayed condition of Kosmoceratops, and recoded C. belli as having both an embayed and non-embayed condition (sensu Campbell et al. 2016; states 0 and 1); the polymorphic state for $C$. belli was done to account for the condition in YPM 2016 and AMNH 5402 (sensu Campbell et al. 2016). Despite these recodings, the phylogenetic analysis of Mallon et al. (2016) still retained a sister-taxon relationship between Kosmoceratops and Vagaceratops. In contrast, the specimen-based phylogenetic analyses of Campbell et al. (2016) and the present study recover Chasmosaurus and $V$. irvinensis as forming a monophyletic clade (Fig. 3). Our revised character codings for AMNH 5402 improved the resolution within this clade, resulting in $V$. irvinensis specimens (CMN 41357 and TMP 1987.045.0001) forming a clade that is well-nested among Chasmosaurus specimens (Fig. 3B). The topology of our (Chasmosaurus + Vagaceratops) clade resembles that of Holmes et al. (2001: fig. 12), in which they recovered a ( $C$. russelli $+(C$. belli $+C$. irvinensis $))$ clade. However, in our analysis, the placement of $C$. russelli specimens has a more scattered distribution, with the holotype (CMN 8800) as an outgroup to $V$. irvinensis specimens, YPM 2016, and AMNH 5402, and other $C$. russelli specimens as forming an unresolved polytomy at the base of the (Chasmosaurus + Vagaceratops) clade. The well-nested position of $V$. irvinensis within Chasmosaurus in our study (Fig. 3B) suggests that Vagaceratops should be subsumed into Chasmosaurus, although this well-nested position is only weakly supported, with a Bremer value of 1 for the clade containing all Chasmosaurus and Vagaceratops specimens except for AMNH 5656, CMN 2280, and TMP 1983.025.0001 (Fig. 3B). As such, we tentatively reassign $V$. irvinensis to Chasmosaurus (sensu Holmes et al. 2001). Future phylogenetic analyses including more specimens are needed to corroborate or refute this hypothesis.

\section{Temporal range extension of Chasmosaurus irvinensis}

YPM 2016 was collected approximately $26.5 \pm 5 \mathrm{~m}$ above the top of the Oldman Formation (Campbell et al. 2016), corresponding to the upper part of the CentrosaurusCorythosaurus Zone (Fig. 2; Ryan and Evans 2005). This horizon is approximately $25.5 \mathrm{~m}$ below the previously known stratigraphic range of $C$. irvinensis - a narrow interval between $52 \pm 5 \mathrm{~m}$ (TMP 2011.053.0046) and $\geq 58 \pm 5 \mathrm{~m}$ (TMP 1998.102.0008) above the Oldman Formation, in the Lambeosaurus magnicristatus-pachyrhinosaur Zone (Campbell et al. 2016, 2018). The precise stratigraphic position of the C. irvinensis holotype (CMN 41357) is unknown, but it was collected below the LCZ, from a horizon likely between 0 and $10 \mathrm{~m}$ below the base of the LCZ (i.e., between 45 and $55 \mathrm{~m}$ above the base of the DPF, as exposed in DPP; Holmes et al. 2001; MJR, pers. obs.). TMP 1998.102.0008 was collected near Onefour from the basal lag bonebed in Complex Mud-Filled Incised Valley No. 1, which lies approximately $3 \mathrm{~m}$ above the base of the LCZ (Eberth 1996: fig. 12; Fig. 2); however, due to the depth of the incision cut (approximately $16 \mathrm{~m}$ ), this specimen may be much younger. TMP 2009.034.0009 was collected from a horizon approximately $33.5 \pm 5 \mathrm{~m}$ above the Oldman Formation, in the lower part of the StyracosaurusLambeosaurus lambei Zone (Fig. 2; D. Eberth, pers. comm.). The low stratigraphic positions of YPM 2016 and TMP 2009.034.0009 could account for the morphological differences between these skulls and those of $C$. irvinensis. If the morphologies exhibited by YPM 2016 and TMP 2009.034.0009 are precursors to the condition seen in C. irvinensis, as we suggest, this would indicate that the acquisition of five posterior epiossifications (either five epiparietals, or four epiparietals and one epiparietosquamosal) occurred prior to the last occurrence of C. belli (CMN 2245) or C. russelli (CMN 8800) (Fig. 2). This indicates that the lineage leading to $C$. irvinensis has a large degree of stratigraphic overlap with that of $C$. belli and C. russelli (Fig. 2). Morphological differences between YPM 2016, TMP 2009.034.0009, and C. irvinensis specimens may be due to evolutionary changes including a reduction in the parietal fenestra length-to-width ratio, a lengthening of the epiparietals, and a coalescence of the epiparietals at their bases (Fig. 2). These inferred evolutionary changes are difficult to test, however, given the lack of specimens between these two stratigraphic intervals.

The lack of stratigraphic separation between the lineage leading to $C$. irvinensis and other species of Chasmosaurus contradicts previous reports that these taxa formed a faunal succession, corresponding to the upper (Lambeosaurus magnicristatus-pachyrhinosaur Zone ), and lower to middle (Centrosaurus-Corythosaurus and Styracosaurus- 
Lambeosaurus lambei zones) units of the DPF, respectively (Holmes et al. 2001; Ryan and Evans 2005). The stratigraphic ranges of these two taxa cannot be explained by an anagenetic model, whereby C. belli or C. russelli evolved into, and was entirely replaced by, $C$. irvinensis over time. The alternative evolutionary model of cladogenesis must therefore be accepted. This also indicates that the presence of Chasmosaurus skulls exhibiting five posterior epiossifications per side (i.e., C. irvinensis and C. irvinensis-like skulls) should no longer be used as a unique component of the faunal assemblage of the Lambeosaurus magnicristatus-pachyrhinosaur Zone. There may also be stratigraphic overlap between Chasmosaurus and Mercuriceratops (Ryan et al. 2014) in the lower DPF and age-equivalent sediments of the Judith River Formation. The close stratigraphic clustering of the centrosaurines Albertaceratops (Ryan 2007), Medusaceratops (Ryan et al. 2010; Chiba et al. 2018), and Wendiceratops (Evans and Ryan 2015) in the lower Oldman Formation and age-equivalent sediments of the Judith River Formation suggests that these taxa also lived contemporaneously.

\section{The presence of postorbital horncores in Chasmosaurus irvinensis}

Holmes et al. (2001) noted that the postorbital dorsal surface in their referred specimens of $C$. irvinensis (CMN 41357, TMP 1987.045.0001) were characterized by a rugose, pitted mound, instead of a horncore (Fig. 5A-D). They interpreted this as evidence that $C$. irvinensis never possessed postorbital horncores and incorporated this character into their diagnosis of this taxon. However, they did acknowledge that the pitted surface may instead represent the base of a resorbed horncore.

YPM 2016 also has rugose postorbital mounds (Fig. 5E, F), while the osteologically less mature skull AMNH 5402 has short (approximately $70 \mathrm{~mm}$; Godfrey and Holmes 1995) postorbital horncores with pointed, unmodified apices (Fig. $5 \mathrm{G}, \mathrm{H})$. If these two skulls represent basal members of the lineage leading to $C$. irvinensis, this may suggest that the postorbital mounds in this taxon are a result of ontogenetic remodelling, as has also been suggested for $C$. belli and $C$. russelli (Campbell et al. 2016). Alternatively, this may be indicative of the evolutionary loss of postorbital horncores in C. irvinensis. The nasal horncore of AMNH 5402 also has an unmodified, pointed apex (Fig. 5G, H), unlike those of other $C$. irvinensis specimens, which have rounded apices, and likely also underwent remodelling (Fig. 5A-F).

\section{SYSTEMATIC PALAEONTOLOGY}

Suborder CERATOPSIA Marsh, 1890

Clade NEOCERATOPSIA Sereno, 1986

Family CERATOPSIDAE Marsh, 1888
Subfamily CHASMOSAURINAE Lambe, 1902

Genus Chasmosaurus Lambe, 1914b

Generic diagnosis (emended from Campbell et al. 2016): Chasmosaurus is diagnosed based on the following unique combination of characters: (1) premaxillary flange along entire anterior margin of external naris; (2) postorbital horncores, when present, curve posteriorly along their length; (3) squamosal dorsal border laterally adjacent to dorsal temporal fenestra straight in profile, anteriorly at level with base of postorbital horncore, and sloping posteroventrally at a shallow angle before ascending farther posteriorly to form lateral border of parietal fenestra; (4) medial margin of squamosal, where it articulates with the lateral bar of the parietal, straight; (5) frill broadens posteriorly to form rectangular to triangular-shaped shield with maximum width more than twice the skull width at orbits; and (6) parietal fenestrae large, occupying most of the parietal.

Type species: Chasmosaurus belli (Lambe, 1914b). Specific diagnosis (emended from Campbell et al. 2016): Medial margin of posterior parietal bar nearly straight or shallowly embayed with the left and right halves meeting at an angle of not less than $136^{\circ}$.

Distribution (emended from Campbell et al. 2016): Middle beds of the Dinosaur Park Formation [DPF; Styracosaurus-Lambeosaurus lambei Zone of Ryan and Evans (2005)] of Alberta [Dinosaur Provincial Park (DPP)], Canada. Synonymies: Monoclonius belli (Lambe, 1902); Ceratops belli (Hatcher et al., 1907); Protorosaurus belli (Lambe, 1914a).

Type specimen: CMN 0491, a partial parietal. Although fragmentary, the holotype is diagnostic based on the combination of generic character 6 and specific character 1 (shallow posterior embayment), a combination not observed in any other chasmosaurine.

Assigned specimens: CMN 2245, NHMUK R4948, and ROM 843.

\section{Chasmosaurus russelli (Sternberg, 1940)}

Specific diagnosis (from Campbell et al. 2016): Medial margin of posterior parietal bar moderately to deeply embayed, with the two halves of the bar forming an angle of between $89^{\circ}$ and $128^{\circ}$ at the midline.

Distribution: Lower to upper beds of the DPF [Centrosaurus-Corythosaurus, Styracosaurus-Lambeosaurus lambei, and Lambeosaurus magnicristatus-pachyrhinosaur zones of Ryan and Evans (2005)] of Alberta (DPP, Hilda, Manyberries, Onefour) and Saskatchewan (Saskatchewan Landing Provincial Park), Canada.

Synonymies: Mojoceratops perifania Longrich, 2010.

Type specimen: CMN 8800, a mostly complete skull 
lacking the lower jaws and part of the rostral, part of the jugals from both sides, part of the right quadrate, squamosal, and parietal.

Assigned specimens: AMNH 5656, CMN 2280, CMN 8803, CMN 41933, TMP 1983.025.0001, TMP 1997.132.0002, and TMP 1999.055.0292.

\section{Chasmosaurus irvinensis Holmes et al., 2001}

Specific diagnosis (emended from Holmes et al. 2001): Chasmosaurus irvinensis is diagnosed based on the following combination of characters: (1) transversely broad snout; (2) nasal horncore short and transversely broad; (3) jugal notch on anterior squamosal broadly rounded and open (not parallel-sided); (4) squamosal tapers little posteriorly, subrectangular in outline, and projects almost directly laterally; (5) posterior parietal margin straight in dorsal view, bearing no median emargination; (6) each side of the posterior parietal margin bears either five epiparietals or four epiparietals and one epiparietosquamosal; (7) epiparietals 1-4 triangular and oriented anterodorsally, and epiparietal 5 or epiparietosquamosal triangular, straight and oriented posterolaterally in the plane of the frill; and (8) dorsal margin of the posterior parietal bar underlying epiparietals $1-4$ curved anterodorsally, forming a dorsoventrally-thickened 'ridge'. The ridge on each side of the posterior parietal bar are connected medially.

Distribution: Uppermost beds of the DPF [Lambeosaurus magnicristatus-pachyrhinosaur Zone of Ryan and Evans (2005)] of Alberta [DPP, Hilda (South Saskatchewan River), Irvine, Manyberries, Onefour], Canada.

Type specimen: CMN 41357, a mostly complete skull and skeleton.

Assigned specimens: TMP 1987.045.0001, TMP 1998.102.0008, and TMP 2011.053.0046.

\section{Chasmosaurus sp.}

The following specimens are referable to Chasmosaurus, but cannot be assigned to species as they do not preserve the diagnostic medial margin of the posterior parietal bar: AMNH 5401 (holotype: Chasmosaurus kaiseni Brown, 1933), CMN 1254 (holotype: Monoclonius canadensis Lambe, 1902; Ceratops canadensis (Hatcher et al. 1907); Eoceratops canadensis (Lambe 1915); Chasmosaurus canadensis (Lehman 1990)), CMN 8801, CMN 8802, CMN 34829, CMN 34832, ROM 839 (holotype: Chasmosaurus brevirostris Lull, 1933), TMP 1979.011.0147, TMP 1981.019.0175, TMP 1993.082.0001, and UALVP 40 . The following specimens are also referable to Chasmosaurus sp., as their posterior parietal margin and epiparietals are intermediate between $C$. belli and $C$. irvinensis: AMNH 5402, TMP 2009.034.0009, and YPM 2016.
Distribution: Chasmosaurus sp. specimens with known stratigraphy were collected from the lower (CentrosaurusCorythosaurus Zone; CMN 8801, TMP 1979.011.0147, TMP 1981.019.0175, UALVP 40, YPM 2016), middle (Styracosaurus-Lambeosaurus lambei Zone; ROM 839, TMP 2009.034.0009), and upper (Lambeosaurus magnicristatus-pachyrhinosaur Zone; TMP 1993.082.0001) units of the DPF. CMN 8802 was collected from the uppermost Oldman Formation of southern Alberta (Milk River region), below the Lethbridge Coal Zone, and is likely age-equivalent to the middle or upper unit of the DPF (Campbell et al. 2018); all other Chasmosaurus sp. specimens were collected from DPP.

\section{SUMMARY}

In this study, we redescribe two skulls previously referred to C. belli (AMNH 5402 and YPM 2016). These two skulls have (YPM 2016) or are inferred to have had (AMNH 5402) five posterior epiparietals, as well as a straight posterior parietal margin - the combination of which is unique to $V$. irvinensis. Based on our new morphological observations and interpretations of these skulls, we recover $V$. irvinensis as a species of Chasmosaurus (C. irvinensis), although the interrelationships of $C$. irvinensis, $C$. belli, and C. russelli remain unclear. We refrain from formerly assigning YPM 2016 and AMNH 5402 to C. irvinensis, however, as their epiparietals are significantly shorter than those of $C$. irvinensis; instead, we reassign these two skulls as Chasmosaurus sp. Given the low stratigraphic position of YPM 2016 (unknown in AMNH 5402) relative to $C$. irvinensis, we consider the morphology of YPM 2016 to be a precursor to that of $C$. irvinensis. If our assessment is correct, this would indicate that the lineage leading to $C$. irvinensis has a large degree of stratigraphic overlap with that of C. belli and $C$. russelli. The close phylogenetic relationship and supposed stratigraphic separation for these three taxa reported in previous studies were used to suggest that they may represent an anagenetic lineage, whereby $C$. russelli evolved into C. belli, and C. belli evolved into, and was entirely replaced by, the latter. However, the lack of stratigraphic separation between these three taxa indicates that they instead arose via cladogenesis. This suggests that dinosaur faunal turnover rates in the DPF were not as pronounced as previously thought.

\section{ACKNOWLEDGEMENTS}

We would like to thank the following people for providing collections access at their respective institutions: M. Norell and C. Mehling (American Museum of Natural History), K. Shepherd, M. Currie, and C. Kennedy (Canadian 
Museum of Nature), B. Strilisky and G. Housego (Royal Tyrrell Museum of Palaeontology), and C. Norris and D. Brinkman (Yale Peabody Museum). Thank you to C. Brown, K. Chiba, D. Eberth, M. Loewen, J. Mallon, and D. Tanke for insightful discussions. Financial support was provided by an Ontario Graduate Scholarship to JAC. We would also like to thank reviewers D. Fowler and S. Maidment, and editor J. Mallon for their comments and for improving the quality of this paper.

\section{LITERATURE CITED}

Brown, B. 1933. A new longhorned Belly River ceratopsian. American Museum Novitates 669:1-3.

Brown, C.M., and D.M. Henderson. 2015. A new horned dinosaur reveals convergent evolution in cranial ornamentation in Ceratopsidae. Current Biology 25:1-8. DOI: 10.1016/j. cub.2015.04.041.

Campbell, J.A. 2015. A reassessment of the horned dinosaur Judiceratops tigris (Ornithischia: Ceratopsidae) from the Upper Cretaceous (Campanian) of Montana, USA. Canadian Journal of Earth Sciences 52:85-95. DOI:10.1139/cjes-2014-0172.

Campbell, J.A., M.J. Ryan, R.B. Holmes, and C.J. SchröderAdams. 2016. A re-evaluation of the chasmosaurine ceratopsid genus Chasmosaurus (Dinosauria: Ornithischia) from the Upper Cretaceous (Campanian) of western Canada. PLoS ONE 11:e0145805. DOI:10. 1371/journal.pone.0145805.

Campbell, J.A., M.J. Ryan, C.J. Schröder-Adams, D.C. Evans, and R.B. Holmes. 2018. New insights into chasmosaurine (Dinosauria: Ceratopsidae) skulls from the Upper Cretaceous (Campanian) of Alberta, and an update on the distribution of accessory frill fenestrae in Chasmosaurinae. PeerJ 6:e5194. DOI:10.7717/peerj. 5194 .

Chiba, K., M.J. Ryan, F. Fanti, M.A. Loewen, and D.C. Evans. 2018. New material and systematic re-evaluation of Medusaceratops lokii (Dinosauria, Ceratopsidae) from the Judith River Formation (Campanian, Montana). Journal of Paleontology 92:272-288. DOI:10.1017/jpa.2017.62

Currie, P.J., and D.A. Russell. 2005. The geographic and stratigraphic distribution of articulated and associated dinosaur remains, pp. 537-570 in P.J. Currie and E.B. Koppelhus (eds.), Dinosaur Provincial Park: A Spectacular Ancient Ecosystem Revealed. Indiana University Press, Bloomington, Indiana.

Eberth, D.A. 1996. Origin and significance of mud-filled incised valleys (Upper Cretaceous) in southern Alberta, Canada. Sedimentology 43:459-477. DOI:10.1046/j.1365-3091.1996.d01-15.x.

Eberth, D.A. 2005. The geology, pp. 54-82 in P.J. Currie and E.B. Koppelhus (eds.). Dinosaur Provincial Park: A Spectacular Ancient Ecosystem Revealed. Indiana University Press, Bloomington, Indiana.

Eberth, D.A. and A.P. Hamblin. 1993. Tectonic, stratigraphic, and sedimentologic significance of a regional disconformity in the upper Judith River Group (Belly River wedge) of south- ern Alberta, Saskatchewan, and northern Montana. Canadian Journal of Earth Sciences 30:174-200. DOI:10.1139/e93-016.

Evans, D.C., and M.J. Ryan. 2015. Cranial anatomy of Wendiceratops pinhornensis gen. et sp. nov., a centrosaurine ceratopsid (Dinosauria: Ornithischia) from the Oldman Formation (Campanian), Alberta, Canada, and the evolution of ceratopsid nasal ornamentation. PLoS ONE 10:e0130007. DOI:10.1371/ journal.pone.0130007.

Farke, A.A., M.J. Ryan, P.M. Barrett, D.H. Tanke, D.R. Braman, M.A. Loewen, and M.R. Graham. 2011. A new centrosaurine from the Late Cretaceous of Alberta, Canada, and the evolution of parietal ornamentation in horned dinosaurs. Acta Palaeontologica Polonica 56:691-702. DOI: 10.4202/ app.2010.0121.

Godfrey, S.J., and R. Holmes. 1995. Cranial morphology and systematics of Chasmosaurus (Dinosauria: Ceratopsidae) from the Upper Cretaceous of western Canada. Journal of Vertebrate Paleontology 15:726-742. DOI: 10.1080/02724634.1995.10011258.

Goloboff, P.A., J.S. Farris, and K.C. Nixon. 2003. TNT: Tree analysis using new technology. Program and documentation available from the authors and at http://www.lillo.org.ar/phylogeny/tnt.

Goloboff, P.A., J.S. Farris, and K.C. Nixon. 2008.TNT: a free program for phylogenetic analysis. Cladistics 24:774-786.

Hatcher, J.B., O.C. Marsh, and R.S. Lull. 1907. The Ceratopsia. US Geological Survey Monograph 49:1-300.

Holmes, R.B. 2014. The postcranial skeleton of Vagaceratops irvinensis (Dinosauria, Ceratopsidae). Vertebrate Anatomy Morphology Palaeontology 1:1-21. DOI: 10.18435/B5159V.

Holmes, R.B., C. Forster, M. Ryan, and K.M. Shepherd. 2001. A new species of Chasmosaurus (Dinosauria: Ceratopsia) from the Dinosaur Park Formation of southern Alberta. Canadian Journal of Earth Sciences 38:1423-1438. DOI: 10.1139/e01-036.

Lambe, L.M. 1902. On Vertebrata of the mid-Cretaceous of the Northwest Territory, Part 2. New genera and species from the Belly River Series (mid-Cretaceous). Canadian Geological Survey, Contributions to Canadian Paleontology 3:25-81.

Lambe, L.M. 1914a. On the fore-limb of a carnivorous dinosaur from the Belly River Formation of Alberta, and a new genus of Ceratopsia from the same horizon, with remarks on the integument of some Cretaceous herbivorous dinosaurs. Ottawa Naturalist 27:129-135.

Lambe, L.M. 1914b. On Gryposaurus notabilis, a new genus and species of trachodont dinosaur from the Belly River Formation of Alberta, with description of the skull of Chasmosaurus belli. Ottawa Naturalist 27:145-155.

Lambe, L.M. 1915. On Eoceratops canadensis, gen. nov., with remarks on other genera of Cretaceous horned dinosaurs. Geological Survey of Canada Museum Bulletin 12:1-49.

Lehman, T.M. 1990. The ceratopsian subfamily Chasmosaurinae: sexual dimorphism and systematics, pp. 211-229 in K. Carpenter and P. Currie (eds.), Dinosaur Systematics: 
Perspectives and Approaches. Cambridge University Press, New York, New York.

Longrich, N.R. 2010. Mojoceratops perifania, a new chasmosaurine ceratopsid from the late Campanian of western Canada. Journal of Paleontology 84:681-694. DOI: 10.1666/09-114.1.

Longrich, N.R. 2014. The horned dinosaurs Pentaceratops and Kosmoceratops from the upper Campanian of Alberta and implications for dinosaur biogeography. Cretaceous Research 51:292-308. DOI: 10.1016/j.cretres.2014.06.011.

Lull, R.S. 1933. A revision of the Ceratopsia or horned dinosaurs. Yale Peabody Museum Memoir 3, 175 pp.

Maddison, W.P., and D.R. Maddison. 2011. Mesquite: a modular system for evolutionary analysis. Version 2.75 . Available: http://mesquiteproject.org.

Maidment, S.C.R., and P.M. Barrett. 2011. A new specimen of Chasmosaurus belli (Ornithischia: Ceratopsidae), a revision of the genus, and the utility of postcrania in the taxonomy and systematics of ceratopsid dinosaurs. Zootaxa 2963:1-47. DOI: 10.11646/zootaxa.2963.1.1.

Mallon, J.C., R. Holmes, D.A. Eberth, M.J. Ryan, and J.S. Anderson. 2011. Variation in the skull of Anchiceratops (Dinosauria, Ceratopsidae) from the Horseshoe Canyon Formation (Upper Cretaceous) of Alberta. Journal of Vertebrate Paleontology 31:1047-1071. DOI:10.1080/02724634.2011.601484.

Mallon, J.C., R. Holmes, J.S. Anderson, A.A. Farke and D.C. Evans. 2014. New information on the rare horned dinosaur Arrhinoceratops brachyops (Ornithischia: Ceratopsidae) from the Upper Cretaceous of Alberta, Canada. Canadian Journal of Earth Sciences 51:618-634. DOI: 10.1139/cjes-2014-0028.

Mallon, J.C., C.J. Ott, P.L. Larson, E.M. Iuliano and D.C. Evans. 2016. Spiclypeus shipporum gen. et sp. nov., a boldly audacious new chasmosaurine ceratopsid (Dinosauria: Ornithischia) from the Judith River Formation (Upper Cretaceous: Campanian) of Montana, USA. PLoS ONE 11:e0154218. DOI: 10.1371/journal.pone.0154218.

Marsh, O.C. 1888. A new family of horned dinosaurs from the Cretaceous. American Journal of Science, series 3, 36:477-478.

Marsh, O.C. 1890. Description of new dinosaurian reptiles. American Journal of Science, series 3 39:81-86.

Ryan, M.J. 2007. A new basal centrosaurine ceratopsid from the Oldman Formation, southeastern Alberta.
Journal of Paleontology 81:376-396. DOI:10.1666/00223360(2007)81[376:ANBCCF]2.0.CO;2.

Ryan, M.J. and D.C. Evans. 2005. Ornithischian dinosaurs, pp. 312-348 in P.J. Currie and E.B. Koppelhus (eds.), Dinosaur Provincial Park: A Spectacular Ancient Ecosystem Revealed. Indiana University Press, Bloomington, Indiana.

Ryan, M.J., A.P. Russell, and S. Hartman. 2010. A new chasmosaurine ceratopsid from the Judith River Formation, Montana, pp. 181-188 in M.J. Ryan, B.J. Chinnery-Allgeier and D.A. Eberth (eds.). New Perspectives on Horned Dinosaurs. Indiana University Press, Bloomington, Indiana.

Ryan, M.J., D.C. Evans, P.J. Currie, and M.A. Loewen. 2014. A new chasmosaurine from northern Laramidia expands frill disparity in ceratopsid dinosaurs. Naturwissenschaften 101:505512. DOI: $10.1007 / \mathrm{s} 00114-014-1183-1$.

Ryan, M.J, D.C. Evans, P.J. Currie, C.M. Brown, and D.B. Brinkman. 2012. New leptoceratopsids from the Upper Cretaceous of Alberta, Canada. Cretaceous Research 35:69-80. DOI: 10.1016/j.cretres.2011.11.018.

Sampson, S.D., M.A. Loewen, A.A. Farke, E.M. Roberts, C.A. Forster, J.A. Smith, and A.L. Titus. 2010. New horned dinosaurs from Utah provide evidence for intracontinental dinosaur endemism. PLoS ONE 5:1-12. DOI: 10.1371/journal. pone.0012292.

Sereno, P.C. 1986. Phylogeny of the bird-hipped dinosaurs (order Ornithischia). National Geographic Research 2:234-256.

Sternberg, C.M. 1919. Field notes, Summer 1919. Unpublished field notes archieved at the Canadian Museum of Nature, Ottawa, Canada.

Sternberg, C.M. 1936. Preliminary map 969A, Steveville sheet, Alberta. Geological Survey of Canada Paper 36-18.

Sternberg, C.M. 1940. Ceratopsidae from Alberta. Journal of Paleontology 14:468-480.

Swofford, D.L. 2002. PAUP: Phylogenetic Analysis Using Parsimony. Version 4.0b10. Sinauer Associates, Inc., Sunderland, Massachusetts.

Wick, S.L. and T.M. Lehman. 2013. A new ceratopsian dinosaur from the Javelina Formation (Maastrichtian) of West Texas and implications for chasmosaurine phylogeny. Naturwissenschaften, 100:667-682. DOI:10.1007/s00114013-1063-0. 


\section{Appendix 1. Revised character state codings for AMNH 5402}

(93) Epiparietals, number per side (Holmes et al. 2001, character 28, modified by Campbell et al. 2016):

(0) - three.

(1) - four or more.

AMNH 5402 was changed from ' 0 ' to ' 1 '.

(100) Epiparietal, P2 shape (Sampson et al. 2010, character 100, modified by Campbell et al. 2016):

(0) - low D-shaped process.

(1) - elongate, flattened process or spike.

(2) - strongly recurved triangular or recurved, low rugose triangular process.

(3) - well-developed triangular process.

(4) - elongate low process.

AMNH 5402 was changed from ' 0 ' to '?'.

(101) Epiparietal P2 curvature (Sampson et al. 2010, character 101, modified by Campbell et al. 2016):

(0) - straight.

(1) - medially or laterally curved in the plane of the frill.

(2) - recurved onto dorsal surface of frill.

AMNH 5402 was changed from ' 0 ' to '?'.

(102) Epiparietal P3 shape (Sampson et al. 2010, character 102, modified by Campbell et al. 2016):

(0) - low raised D-shaped process.

(1) - elongate spike.

(2) - strongly recurved triangular or recurved, low rugose triangular process.

(3) - well-developed triangular process.

(4) - elongate, low process.

AMNH 5402 was changed from ' 0 ' to '?'.

(153) Epiparietal P4 shape (Campbell et al. 2016, character 153):

(0) - low raised D-shaped process.

(1) - strongly recurved triangular or recurved low gnarled triangular process.

(2) - well-developed triangular process.

(3) - elongate, low process.

AMNH 5402 was changed from '?' to ' 0 '.

(154) Epiparietal, P4 orientation (Campbell et al. 2016, character 154):

(0) - epiparietal oriented in the plane of the frill.

(1) - directed anterodorsally.

AMNH 5402 was changed from '?' to ' 0 '.

(155) Epiossification in P5 position, shape (Campbell et al. 2016, character 155):

(0) - low raised D-shaped process.

(1) - well-developed triangular process.

(2) - elongate low process.

AMNH 5402 was changed from '?' to ' 1 '. 
Appendix 2. Data matrix used in phylogenetic analysis.

'Lepto_grac'

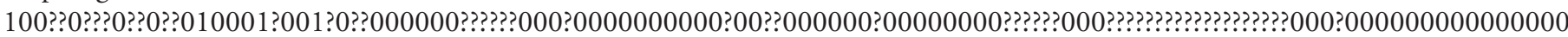
$0001 ? 000000000000 ? 0 ? 000000(01) ? 0 ? ? ? ?$

'Proto_andrew'

000??0???0??0??01000110000100000000??????000?0000000000?0100110000?000001000000000000???????????????????000000000000000 $0000000100000000000000000000000 ? 0$ ????

'Zuni_christ'

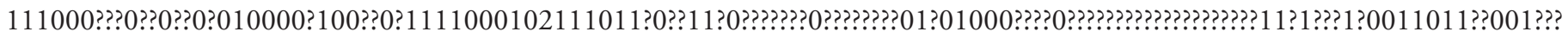
?1100?????????01?0??1??????

'Turano_tardarb'

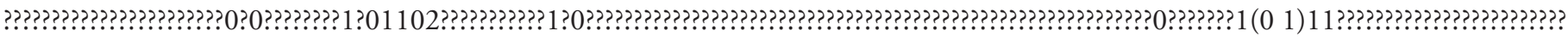
?????

'Alberta_nesmoi'

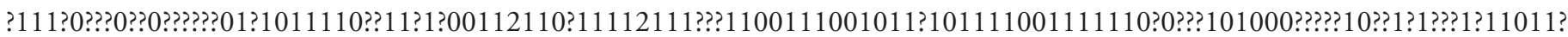

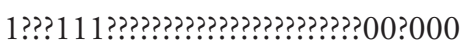

'Centro_apertus'

011110?0?0??0??111001?1111110101111000022110?1111211111011001110010110101111031111110?0000101001113210011111 $1111111011111111111111110111111111011111(0$ 1)000000

'Pachy_lakust'

011110?0?0??0??111001?111112010111111????111111112?111101100111001011010111103111111??0???1?1000???211010111111? 1110111111111111?1?10??11111110111??(0 1)00?000

'Kosmo_rich'

$1110011111001100001000111111000111110111111111011011110111120010112211101110001001(0$ 1)1111321110101213222

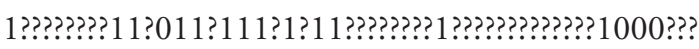

'Aguja_maris' 111001010110100000111?11111100011111011001111101101111??111?1011112?11??1110?20111011?111?0???01???????111111???1 10?1111??1?111111110????111?11111??1000???

'Utah_gettyi'

11100101110?11000011001111110001111111022111110110?1111111111011112111101110120111011112210?00013133030???1 111?111011111111111???1?10??????1??11111?1000???

'Penta_stern' $1110010111111100001100111111000111110011211111(0$ 1)11111111111111011112211101110120111011112210?0001313303 0 ?11111111110111111111111111110?1111111111?11??000???

'Coahuila_magna'

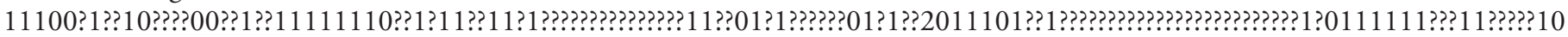

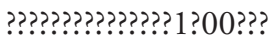

'Anchi_ornatus' 1110011(0 1)1110110001001?11111100011111111111111101101111111112101110?11110111100(0 1)10101111220(0 1)2(0 1)0 013233030111111111?1?01?11???111??????????????????????000020?

'Arrhino_brachy' 1110011??1?0100001?01?1111110001111?:111111111101101111(0 1)1111110111(0 1)0111101111001101011?111012000140040 401111111111110111111??111?1??1????????????????0001??? 
'Ojo_fowl'

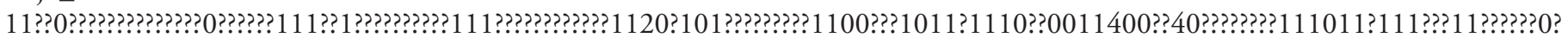

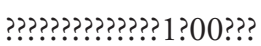

'Toro_latus'

1110010??111???0010?1?111111100111111(0 1)112111110112111?(0 1)11111101110?(0 1)12101011031201011?11100?10014004 040111111111 ?1????????1111???1?10????????????????(0 1)00302

'Toro_utah'

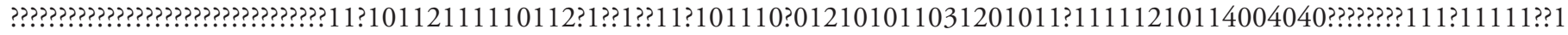

?111?11??????????????????1???302

'Eotri_xerin'

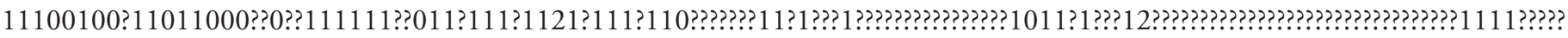

??????????????????1????

'Nedo_hatch'

11100100?11111100?0?1?111?1110011?1?10112?11110?12?1?11111111?101???021?1111031101011?11101????1??????????111???????????

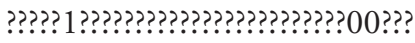

'Tri_horr'

11100100?111111001001?11111110011111101121111101121111111111101010?00211001??????1011?1110120011400404011111 $11111101111111111111111111111111111111111(0$ 1)00???

'Tri_pror'

11100100?111111001001?11111110011111101121111101121111011111101010?00211001??????1011?1110120011400404011111 111111011111111111111 ??1??????????????11(0 1)00???

'AMNH_5401'

1110010101001000001000111?110011111?01102111111110111111111110?11???12101110?00111011?1?100?????????????11?1?1????? ?????????11???????????????????????000????

'AMNH_5402'

1110010101?010000?101?111?110011111?000?21111111121111111111110?110??12101110000211010?1?100?1001000???0?11?1?1? 1110 ?111111??11??????????????????????1000001

'AMNH_5656'

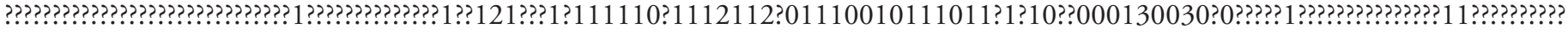

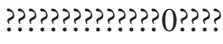

'CMN_0491'

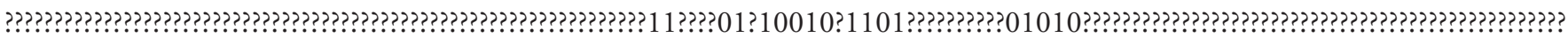

???????

'CMN_1254'

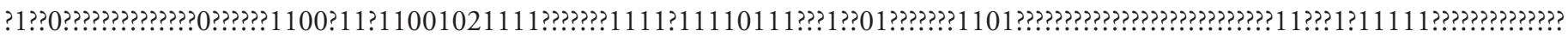
???????????1??????

'CMN_2245'

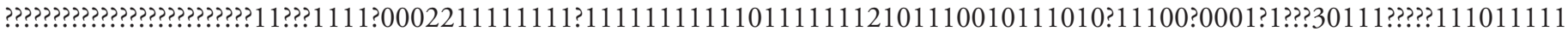
111111111111001 ??1?1?1??11111000???

'CMN_2280'

1110010101?0100000101?111111001111110000211111111211111111111011112110101110010111011?11100?00013103030?11? ??1?1110?11111111111111110?1??11111111???1000???

'CMN_8800'

1110010101?010000?:?:00111?11001111110????1111??1???11111111110?1112112101110010111011?11100?00010100030??????1?????

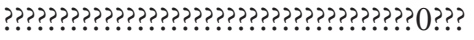


'CMN_41357'

111001?1010010000010??1?1111001111???????111111?121111111111101110??12?01110000011011?11100?11012132221??????1?11

101111111?1111111?10?1111???11??11?1000111

\section{'NHMUK_R4948'}

1110010101?010000??0??11111100?111110????11111111211111?11111011111112?01?10010111011?11100???????????????1??1??110???? 11 ??1?11111111?01????1????111??000???

'ROM_839'

111001010100100000101?1111110011111?00002111111110111111111110111???12101110010111011?11100??0?????????111?111? 11101111111111 ???????????????????????1000???

'ROM_843'

?1100??1????????00101?1111110011111?0????11111111011111111111011111210101110010211011?11100?00010103?30?11?111?11 ???111111111111?1?1001111?1?111111?1000???

'TMP_81.19.175'

111001010100100000101?11111100111111010?2111111112111111111??0111???1?10111??10?11010?1????????????????111?111????????

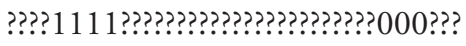

'TMP_83.25.1'

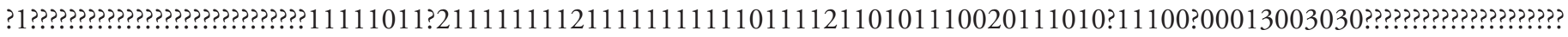

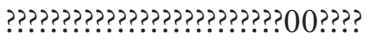

'TMP_87.45.1'

111001?1010010000??01?11111100?11???????? 111111112111111111110111 ???12101110???011011?111012????????????11???1??????????? ??111???????????????????????000111

'UALVP_40'

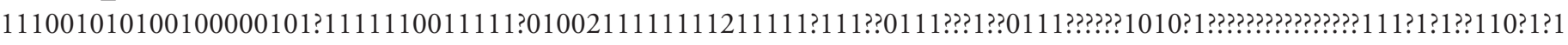

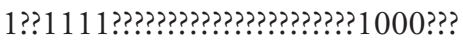

'YPM_2016' 11100111010010000?101?111111001111110????1111111121111111111101110??12101110010211011?11100?10010100001111?1?

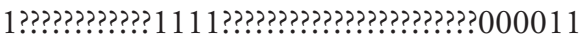

'Judi_tigris'

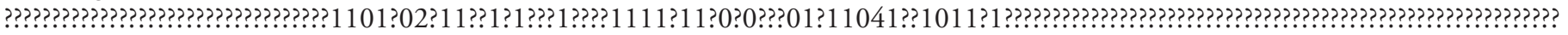
??????????

'Bravo_poly'

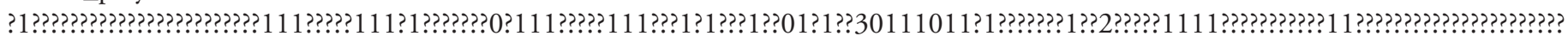
??????1110??? 